Research Article

\title{
Reflection Crack Analysis of Asphalt Overlay on Cement Concrete Pavement Based on XFEM
}

\author{
Qiang Li $\left(\mathbb{D},{ }^{1,2}\right.$ Zhixiang Chen $\mathbb{D},^{1}$ and Shaohui Luo $\mathbb{D}^{1}$ \\ ${ }^{1}$ School of Traffic and Transportation Engineering, Changsha University of Science and Technology, Changsha 410114, China \\ ${ }^{2}$ National Engineering Laboratory for Highway Maintenance Technology, Changsha University of Science and Technology, \\ Changsha 410114, China
}

Correspondence should be addressed to Zhixiang Chen; 1298221872@qq.com

Received 6 October 2021; Revised 1 December 2021; Accepted 9 December 2021; Published 20 December 2021

Academic Editor: Ragip Ince

Copyright ( $\odot 2021$ Qiang Li et al. This is an open access article distributed under the Creative Commons Attribution License, which permits unrestricted use, distribution, and reproduction in any medium, provided the original work is properly cited.

\begin{abstract}
Based on the improved Paris formula, the reflection cracking characteristics of asphalt overlay on the cement concrete pavement are carefully scrutinized. The fatigue life is also predicted through the indoor simulation tests and establishing the two- and threedimensional extended finite-element method (XFEM) models. Four fracture factors of the Paris formula in the asphalt mixture are appropriately calculated by fitting the $\mathrm{N}-\mathrm{a}$ curve of the indoor test, and their predicted values are then exploited in the numerical simulations. The obtained results show that the numerical model can successfully predict the results of the indoor simulation test. It indicates that the XFEM has apparent advantages in examining the reflection cracking of the asphalt overlay on the cement concrete pavement.
\end{abstract}

\section{Introduction}

Reflective cracks represent the main damage form of asphalt overlay structures on old cement pavements, which will seriously reduce pavement durability and shorten the service life. Therefore, the adoption of effective antireflection crack measures is the key technology for overlaying asphalt pavements on old cement pavements. The crack treatment is a common antireflective crack measure for overlaying asphalt concrete structures on the cement-based pavements, reducing the local stress effect at joints and delaying the initiation and expansion of reflective cracks within the asphalt overlay [1-3]. Li et al. [4] explored the crack resistance of a new anticracking paste through the mechanical testing and simulation (MTS) loading test. Gonzalez-Torre et al. $[5,6]$ and Barraza [7] et al. examined the effectiveness and influence of an antireflective cracking system by utilizing geosynthetics.

In addition, the prediction of fatigue life of crack propagation is beneficial to the design of economical and durable crack resistance materials and overlays' asphalt mixture. Li et al. [8] characterized the fatigue lives of asphalt mixtures with varying asphalt content. Seo and Kim [9] employed the acoustic emission approach to monitor the fatigue damage and healing of the asphalt concrete. Dave and Buttlar [10] scrutinized the reflective cracking mechanism of hot mix asphalt overlays on different cement concrete pavements. Mac et al. [11] studied the fatigue life of various reclaimed asphalt pavement mixtures subjected to static and cyclic flexural loads. Isailovic et al. [12] conducted the cyclic uniaxial tension-compression loading tests for the stress-control mode, investigating the relationship between the fatigue life of the asphalt mixture and the stiffness recovery phenomenon.

The fatigue cracking of asphalt structural layers can also be simulated by laboratory tests; nevertheless, the obtained test data are often discrete. Furthermore, low reproducibility, high test cost, and long test cycle due to the variability of specimen fabrication and reliability of the test equipment or other reasons are among other limitations in conducting experimental tests. So far, the finite-element method (FEM) has been broadly exploited in crack simulations due to its convenience, swiftness, high accuracy, and capability in considering various boundary conditions and loading cases. 
Liu et al. [13] revealed the complex relationship between the generation of macroscopic cracks and crack propagation in the asphalt pavement by a FEM-based cohesive zone model (CZM). Zhang et al. [14] effectively predicted the propagation of doubly parallel cracks in thin plate-like structures subjected to cyclic loading.

However, the structural fracture occurs only at the continuous finite-element interface, and the dense refinement of mesh is employed in the traditional FEM to meet the required accuracy. The extended finite-element method (XFEM), a newly established finite-element-based approach, exploits the standard FEM to model the crack without its precise definition and mesh subdivision. In recent years, these extraordinary characteristics have provided the XFEM as an effective methodology for mechanical examination of cracks from various aspects. Sukumar et al. [15] first applied the XFEM to three-dimensional static crack problems and reported a good agreement between the predicted results and those of the traditional FEM. $\mathrm{Ng}$ et al. [16] examined the fracture behavior of the asphalt mixture in splitting test (ST) based on the XFEM and the image analysis technology. It was proved that the XFEM could accurately predict the fracture behavior of heterogeneous materials such as asphalt mixtures. Yan [17] considered the viscoelastic properties of the asphalt mixture and simulated its corresponding crack propagation via the XFEM, while the efficiency of the model was confirmed. Based on the modified fatigue damage model and dynamic XFEM, Jin [18] addressed the cracking path and the cracking process of the asphalt mixture, recognizing the fatigue life prediction of asphalt pavement structures at various stages. Huang et al. [19] developed a fatigue propagation model for temperature shrinkage reflective cracks in the semirigid-based asphalt pavement by utilizing the XFEM. Wang et al. [20] explored the reflective cracking mechanism of semirigid base asphalt pavements subjected to thermal and traffic coupling dynamic loading via the XFEM. Islam et al. [21] established an XFEM-based crack propagation model for hot mix asphalt overlay pavements acted upon by wheel loads. The results obtained from the indoor indirect tensile test and those of the direct tensile test were also compared to see the accuracy of the established model.

So far, the research on the crack's problems based on the XFEM analysis has been essentially aimed at the crack propagation after the occurrence of bottom cracks in asphalt pavement structure layers. The analyses of crack propagation after treatment of the crack-resistant materials have been rarely involved. In the present study, by employing the XFEM and the indoor model test of the asphalt overlay treated by crack resistance of cement pavement under cyclic loading, the relationship between the fracture parameters of the asphalt mixture and the fatigue reflection cracks of the overlay structure is presented. The equation of reflective cracking fatigue life of the asphalt overlay on the cement concrete pavement is proposed, which can quantitatively evaluate and analyze the anticracking effect of materials.

\section{Laboratory Model Test}

2.1. Asphalt Mixture Design. In the performed tests, the used asphalt mixture type is AC-13C (i.e., SBS modified asphalt of Yueyang Changlian and limestone aggregate of Linxiang). The asphalt-aggregate ratio determined by the Marshall mix design method is $4.9 \%$, and the mineral aggregate gradation is $11-16 \mathrm{~mm}: \quad 6-11 \mathrm{~mm}: \quad 3-6 \mathrm{~mm}: \quad 0-3 \mathrm{~mm}$ : mineral powder $=16: 22: 18: 41: 3$. The gradation design results have been demonstrated in Table 1 .

The immersion Marshall, freeze-thaw splitting, and rutting tests were carried out to study the water damage resistance and high-temperature stability of the designed asphalt mixture. The obtained results have been provided in Table 2. As seen, the asphalt mixture's performance meets the requirements of Chinese "Technical Specification for Asphalt Pavement Construction” (JTG F40 2004).

2.2. Model Structure. The previous comparative test shows that it is difficult to obtain the crack propagation law data of asphalt overlay structures with plate supports. In fact, no apparent cracks are detected in the specimen after severe rutting failure of the asphalt overlay structure. The crack initiation and development process of the joint in the structural layer can be visually observed in the simple support test model. Such ends' condition is taken into account (see Figure 1). The specimens that consist of three anticracking treatments are designed, including macromolecule polymer crack paste, high elastic stress absorption band, and general crack pouring. The asphalt overlay type is AC-13C, while the dimensions of the prismatic specimens are $30 \mathrm{~cm} \times 30 \mathrm{~cm} \times 3 \mathrm{~cm}$. The static pressure approach is employed to control the uniformity of the specimen forming.

2.3. Test Scheme. To provide indoor model test structures, the below steps are followed up sequentially:

(1) The $30 \mathrm{~cm} \times 30 \mathrm{~cm} \times 4 \mathrm{~cm}$ test block is cut by hemp stone to simulate cement concrete pavement. The joint formed by two cement concrete pavement slabs is simulated in the middle of the block, and its lateral size is set equal to $3 \mathrm{~mm}$.

(2) Three kinds of anticracking materials are utilized to treat the joint of the test pieces based on their corresponding construction technology. The crack pouring is to uniformly pour emulsified asphalt many times until the joint is filled. Macromolecule polymer crack paste is then cut to $8 \mathrm{~cm} \times 30 \mathrm{~cm}$, and the center of the hemp stone specimen is paved flatly. Highly elastic stress absorption bands consist of five functional materials, layer-by-layer sticking treatment.

(3) The asphalt mixture specimen, hemp stone test block, and rubber pads, in turn by SBS modified asphalt, are bonded to present a complete experimental model of the asphalt overlay structure for joint treatment on the concrete pavement. 
TABLE 1: Asphalt mixture aggregate gradation design.

\begin{tabular}{lcccccccccc}
\hline \multirow{2}{*}{ Aggregate type } & \multicolumn{1}{c}{ Mass percentage (\%) through the following sieves $(\mathrm{mm})$} \\
& 16 & 13.2 & 9.5 & 4.75 & 2.36 & 1.18 & 0.6 & 0.3 & 0.15 & 0.075 \\
\hline 1\# (11 16 mm) & 100 & 69.1 & 5.3 & 3.7 & 1.7 & 1.4 & 1.1 & 0.8 & 0.5 \\
2\# (6 11 mm) & 100 & 100 & 81.3 & 3.6 & 1.3 & 0.9 & 0.8 & 0.7 & 0.6 & 0.2 \\
3\# (3 6 mm) & 100 & 100 & 100 & 80.4 & 9.6 & 4.3 & 3.5 & 2.9 & 2.2 & 1.0 \\
4\# (0 3 mm) & 100 & 100 & 100 & 99.8 & 89.1 & 66.9 & 46.8 & 34.9 & 22.2 & 8.4 \\
Mineral powder & 100 & 100 & 100 & 100 & 100 & 100 & 100 & 99.8 & 91.1 & 76.4 \\
Synthetic gradation & 100 & 95.1 & 80.7 & 59.8 & 41.8 & 31.6 & 23.2 & 18.1 & 12.4 & 6.1 \\
\hline
\end{tabular}

TABle 2: Performance index test of AC-13C asphalt mixture.

\begin{tabular}{lccc}
\hline Test types & \multicolumn{3}{c}{ Test results } \\
\hline Immersion Marshall test & Marshall stability $(\mathrm{kN})$ & Immersion Marshall stability $(\mathrm{kN})$ & Residual stability $(\%)$ \\
& 14.30 & 12.67 & 88.6 \\
Freeze-thaw splitting test & Split strength $(\mathrm{MPa})$ & Freeze-thaw splitting strength $(\mathrm{MPa})$ & TSR $(\%)$ \\
& 1.080 & 0.959 & 88.9 \\
Rutting test $\left(60^{\circ} \mathrm{C}\right)$ & 6698 & Dynamic stability $($ times $/ \mathrm{mm})$ & 6637 \\
\hline
\end{tabular}

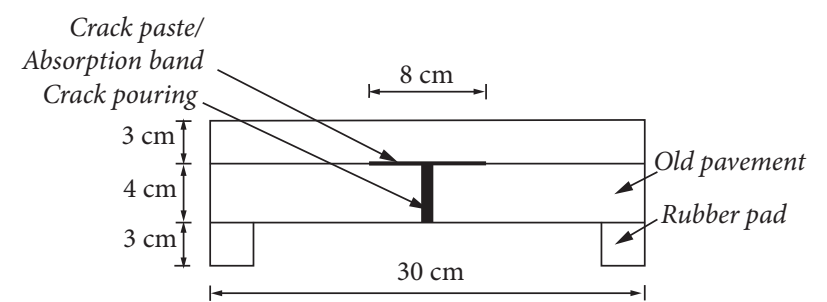

FIGURE 1: Structural model of the anticracking treatment test on the beam-like pavement with simply supported ends.

Additionally, the side of the precracking range of the asphalt mixture is covered by white paint to facilitate the observations and measurements of the crack generation and development (see Figure 2).

The test is conducted by exploiting a DWT double wheel Hamburg rutting instrument. The generation and expansion of reflective cracks are of concern under the driving load exerted by the round-trip wheel. The main test parameters are as follows: the temperature is almost controlled at $25^{\circ} \mathrm{C} \pm 0.5^{\circ} \mathrm{C}$, the grounding pressure of the test wheel is kept fixed at about $0.7 \mathrm{MPa} \pm 0.05 \mathrm{MPa}$, and the action rate is 52 times/min \pm 1 time/min. When the crack completely penetrates the asphalt overlay or the serious groove appears on the surface of the asphalt overlay, the test will be terminated.

2.4. Analysis of Test Results. According to the demonstrated results in Figures 2(a)-2(c), there exist considerable differences in the failure state of the specimens treated by three anticracking procedures at the test's termination. Since the number of wheel loads required for fatigue cracking of the specimen treated by a high elastic stress absorption band is much higher than that of wheel loads for rutting damage, no noticeable reflection cracking is detected until the specimen is severely rutted at the top (see Figure 2(b)). However, the overlay structures are significantly damaged under both macromolecule polymer crack paste and crack pouring, occurring with various degrees of bending (see Figure 2(a)).
Significantly, the separation degree of the crack pouring treatment specimen between the asphalt overlay and the hemp stone block is commonly greater than that of the macromolecule polymer crack paste treatment specimen. This fact demonstrates that the macromolecule polymer crack paste has good adhesion and crack-resistant capability. The crack propagation of the specimen with crack pouring is similar to that of the macromolecule polymer crack paste, which shows that several bottom-up reflective cracks would be generated near the joints of the hemp stone, and the joints appear with obvious opening deformation when the cracks expand to the asphalt overlay surface (see Figure 2(c)).

During performing the test, the width of cracks is measured by digital percentile, while the length of the propagated crack and the reading of percentile are recorded by a high-definition camera. Thereby, the variation of the initial crack and crack propagation within the overlay for a given test loading times can be monitored in the model test of specimens under macromolecule polymer crack paste and crack pouring treatments.

To facilitate the calculations, the projection length of the crack in the vertical direction is taken into account as the crack length in the $N-a$ curve. The relationship between the propagated crack length and the wheel load times can be obtained from the video recording. The crack length, $a$, is evaluated from the video screenshots of the HD camera every 19 minutes (1000 wheel load actions). Combined with the wheel load times $N$ recorded by the Hamburg Rutometer 


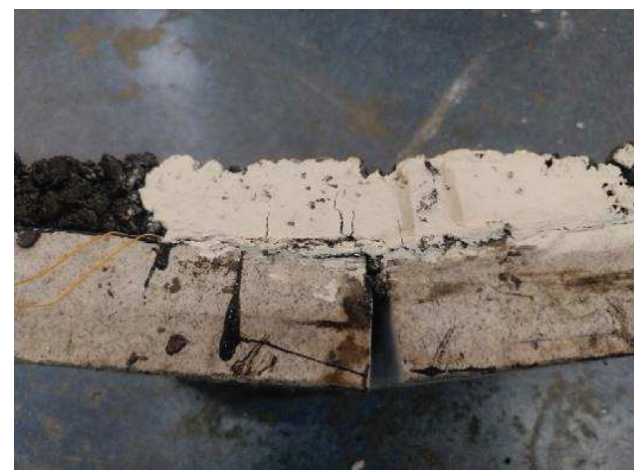

(a)

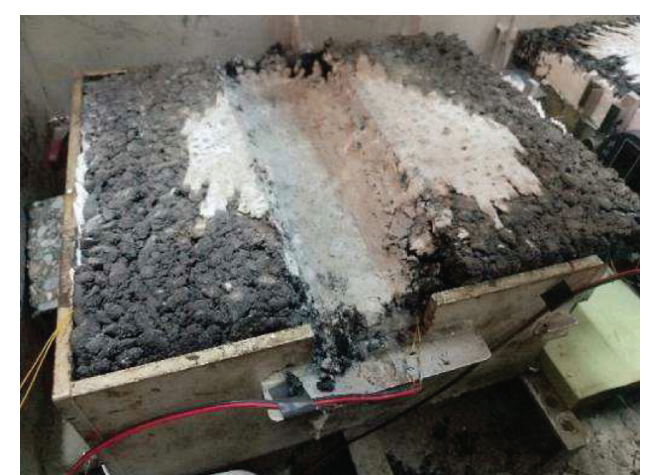

(b)

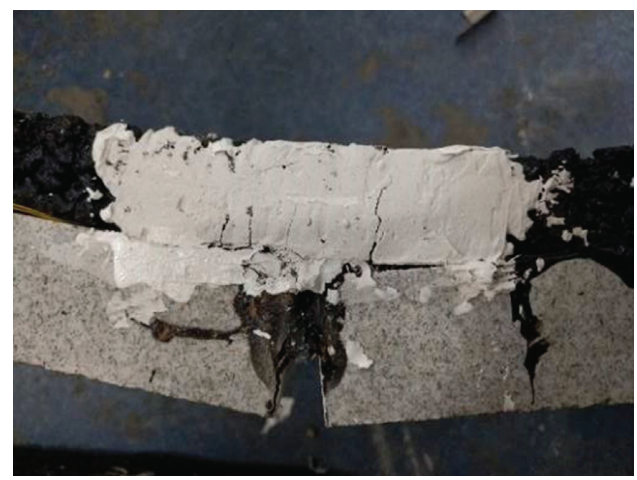

(c)

FiguRE 2: Cracking patterns of specimens based on various treatment schemes. (a) Treatment specimen of the macromolecule polymer crack paste. (b) Treatment specimen of the high elastic stress absorption band. (c) Treatment specimen of the crack pouring.

at various times, the curves associated with the crack length as a function of the load cycle times are obtained, as demonstrated in Figure 3.

Both crack propagation trends are essentially consistent under the driving load exerted by the round-trip wheel load in the DWT double wheel Hamburg rutting instrument. While for the case of the macromolecule polymer crack paste, no obvious plastic deformation occurs due to the strong tensile resistance at the initial stage, and it develops slowly after the appearance of the initial crack, showing powerful crack resistance behavior. The crack propagation rate of the structure treated by the crack pouring is significantly higher than that of the structures treated by the polymer crack paste, indicating that the fatigue cracking life of the treatment structure of the polymer crack paste is longer than that of the ordinary grouting.

\section{Analysis Model via the XFEM}

3.1. Propagation of the Crack Fatigue. In classical dynamics, the structural response of elastic-plastic structure tends to be relatively stable after a certain number of cycles of alternating cyclic loading. For such a circumference, the structural response of each subsequent cycle would be moderately the same as that of the previous one. Therefore, to extract the structural response corresponding to the stable state, the most common approach is to repeatedly calculate the dynamic response under each load cycle until the structure

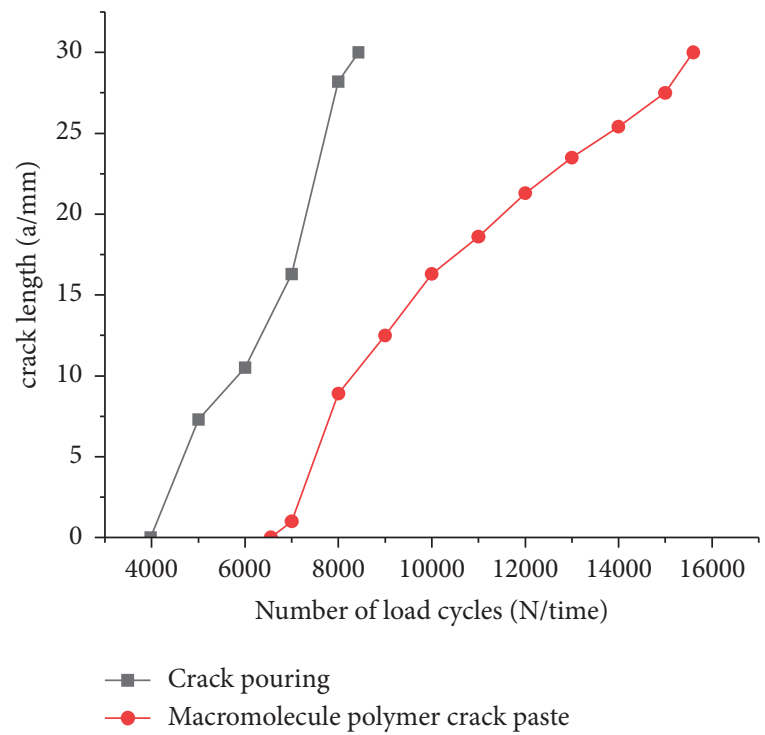

FIGURE 3: $N$ - $a$ curve under common grouting and crack paste resistance treatment measures.

response time exceeds a certain number of cycles or the structure arrives at the relatively stable state.

Direct cyclic analysis in ABAQUS belongs to quasistatic analysis, suitable for large-scale models and complex problem analyses, such as fatigue crack propagation problems. The stable response state of the structure under cyclic 
loading can be achieved by the Fourier expansion and the time integration of nonlinear materials [22]. In dealing with the fatigue crack propagation problem of pavement structures, every step of crack propagation is regarded as a quasistatic process, and the results of the structural stability response in line with the real situation results can be obtained.

Based on the failure criterion employed in the XFEM analysis, the initiation and evolution parameters of damage are controlled to determine damage development. Further, the damage stability factor is exploited to enhance convergence, enabling dynamic crack expansion [23]. In the XFEM, the $J$-integral based on the fracture mechanics theory is utilized as a function of the stress intensity factor. The strength of the stress-strain field at the crack tip is reflected by the $J$-integral; that is, the strain energy release rate $(G)$ determines the crack propagation length and the stress level.

The fatigue crack propagation of materials generally follows three stages [24], as presented in Figure 4.

Low-speed propagation stage: when the cumulative damage of the asphalt overlay reaches 1 , that is, the value of $G$ at the crack tip approaches the threshold level of the strain energy release rate $G_{\text {thresh }}$, the reflective crack generates and expands upward along with the asphalt overlay. The crack propagation speed is high and appears in the stress concentration area. At the end of this stage, the propagation speed gradually slows down and turns to the stable stage of propagation.

The stable crack growth stage: this stage accounts for the largest proportion of time in the whole growth process. When the crack extends to the middle of the asphalt overlay, the bending tensile stress should be maintained. Hence, the crack growth gradually decreases, and the crack growth remains stable until it reaches the upper limit of the strain energy release rate $G_{p l}$, entering into the accelerated growth stage at this time.

Accelerated propagation stage: after the expansion of the previous two stages, the crack can be propagated to the upper part of the asphalt overlay, and the cumulative damage suffered by the structural layer leads to the increase of fatigue. It enters into the rapid cracking stage until the crack runs through the asphalt overlay. At this time, the asphalt overlay losts the structural bearing capacity, and the $G$ approaches the ultimate strain energy release rate $G_{c}$.

In the crack growth curve, each parameter satisfies the following relationship:

$$
\begin{aligned}
\frac{G_{\text {thresh }}}{G_{c}} & =0.01, \\
\frac{G_{p l}}{G_{c}} & =0.85,
\end{aligned}
$$

where $G_{c}, G_{\text {thresh }}$, and $G_{p l}$ are the ultimate, threshold, and upper limit values of the strain energy release rate, respectively.

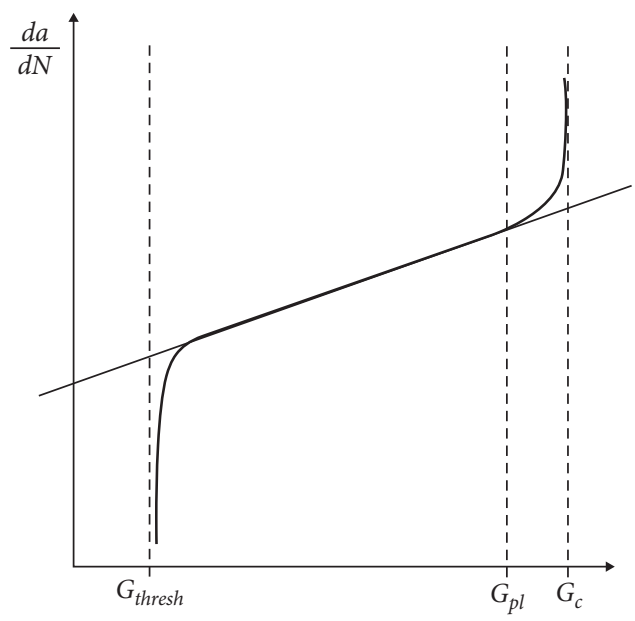

FIgURE 4: Fatigue crack propagation diagram.

The Paris formula predicts the crack propagation in the XFEM analysis as

$$
N_{0}=C_{1}(\Delta G)^{C_{2}},
$$

where $N_{0}$ is the number of load cycles and fracture parameters $C_{1}$ and $C_{2}$ are related to materials. Equation (2) can also be employed for predicting the fatigue life of the first stage of crack propagation:

$$
\frac{d a}{d N}=C_{3}(\Delta G)^{C_{4}},
$$

in which the fracture parameters $C_{3}$ and $C_{4}$ rely on the type of materials. Equation (3) predicts the fatigue life for the second stage of crack propagation.

In general, the remaining fatigue life of the crack propagation associated with the third stage is negligible and can be ignored in calculations.

3.2. The XFEM-Based Model. The extended finite-element structural models of three anticracking measures in the twoand three-dimensional (2D and 3D) states are established, as shown in Figure 5.

The two- and three-dimensional models adopt the same material and fracture parameters as provided in Table 3 . The grid type of the 2D model is CPE4, which is divided into 818 units and 900 nodes using the layout of upper dense and lower sparse, and middle dense and both sides sparse. The grid type of the 3D model is C3D8R. The division adopts the layout of dense middle and sparse sides, divided into 7488 units and 9636 nodes. The node integral adopts the reduced integral mode.

The 3D model is subjected to a moving surface load with a maximum magnitude of $0.7 \mathrm{MPa}$ on the asphalt surface. Concerning the two-dimensional plane model, the surface load should be appropriately transformed into the line load: $770 \mathrm{~N} /(0.022 \mathrm{~m} \times 1 \mathrm{~m})=35 \mathrm{kPa} / \mathrm{m}$. The moving load is perpendicular to the crack direction, the wheel contact area is $5 \times 2.2 \mathrm{~cm}$, and the load cycle period is $0.9 \mathrm{~s}$. In order to realize the moving load, the grid strip of the load movement 


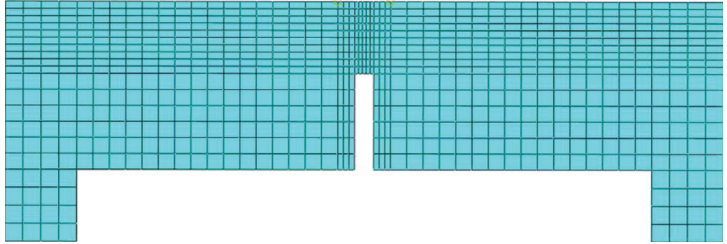

(a)

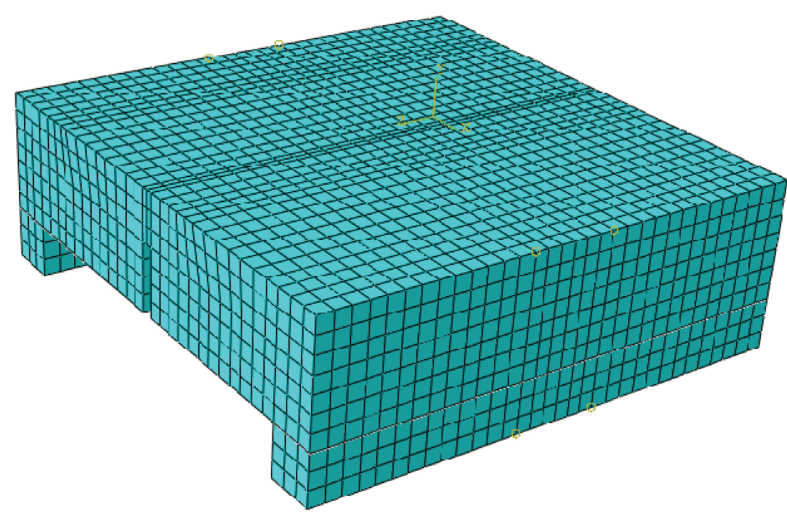

(b)

Figure 5: Meshing of the structure via the XFEM. (a) 2D model. (b) 3D model.

Table 3: Mechanical properties of the constituent materials of the employed model.

\begin{tabular}{lcccc}
\hline Material & Elastic modulus $(\mathrm{MPa})$ & Poisson's ratio & Fracture energy $\left(\mathrm{J} / \mathrm{m}^{2}\right)$ & Fatigue limit $(\mathrm{MPa})$ \\
\hline AC-13 & 1250 & 0.25 & 300 & 0.105 \\
Stress absorption band & 800 & 0.25 & - & - \\
Concrete slab & 3100 & 0.15 & - & - \\
Cracked paste & 200 & 0.25 & - & - \\
Rubber pad & 6.5 & 0.40 & - & - \\
\hline
\end{tabular}

is set on the surface of the asphalt surface. The length and width of each grid are the same as the width of the wheel contact asphalt surface. Each step-time load acts on a grid, as presented in Figure 6.

Boundary conditions: the bottom of the model structure has been completely fixed, the top surface of the load action has been not constrained, and the vertical surfaces of the driving direction are allowed to displace and rotate vertically. The relative slip between the cement plate and the rubber pad would be negligible, and a small sliding contact analysis is adopted.

Assume that the consisting materials of both pavement structural layer and crack-resistant are homogenous with linear elastic behavior, and a notch of opening $3 \mathrm{~mm}$ is set at the bottom of the surface layer in advance. No relative slippage and voids occur between the asphalt mixture and the cement layers, and the interface is continuous. The fracture criterion conforms to the maximum principal stress criterion, and the cracking direction would be perpendicular to the direction pertinent to these maximum values.

The load cycle is carried out by the direct cycle module in ABAQUS, and the input of fracture parameters is required to modify the model keyword module. Specifically, the corresponding keywords composed of fatigue fracture parameters $C_{1}, C_{2}, C_{3}, C_{4}$, and the fracture energy $G$ are edited below. * Surface Behavior, pressure overclosure $=$ HARD in the interaction properties module.

3.3. Fracture Parameters. Asphalt mixtures have complex compositions and heterogeneous microstructures (irregular aggregates, bitumen, voids, and so on), making it

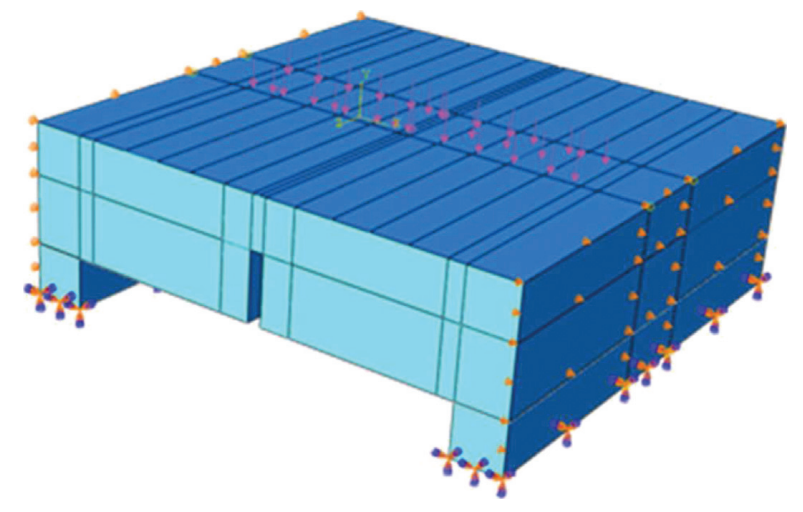

Figure 6: The moving load arrangement and boundary conditions of the XFEM-based model.

challenging to obtain the fracture properties of materials precisely. To ensure the reliability of the source of material parameters, the fracture parameters of the AC-13C material are obtained from the structural simulation test to examine the crack propagation law after performing crack resistance measures. The parameters $C_{1}, C_{2}, C_{3}$, and $C_{4}$, are evaluated by utilizing the plotted $N$-a curves obtained from the indoor model fatigue test. The factors $C_{1}$ and $C_{2}$ are pertinent to the fatigue life of the structure at the initial cracking and can be evaluated by fitting the initial crack fatigue life of the indoor test via equation (2). Further, the parameters $C_{3}$ and $C_{4}$ are calculated by appropriate fitting the curves of $\ln (\mathrm{d} a / \mathrm{d} N)$ in terms of $\ln (\Delta G)$ in double logarithmic coordinates using equation (3), and the $\mathrm{d} a / \mathrm{d} N$ can be derived from the $N-a$ curve fitting and derivation. The fracture parameters obtained from the test are presented in Table 4. 
TABLE 4: Model fracture performance parameters.

\begin{tabular}{|c|c|c|c|c|c|c|c|c|}
\hline \multirow{2}{*}{ Material type } & \multicolumn{4}{|c|}{ Fracture parameters under 2D conditions } & \multicolumn{4}{|c|}{ Fracture parameters under 3D conditions } \\
\hline & $C_{1}$ & $C_{2}$ & $C_{3}$ & $C_{4}$ & $C_{1}$ & $C_{2}$ & $C_{3}$ & $C_{4}$ \\
\hline Crack pouring & 6712 & -0.1212 & $1.5249 \times 10^{-6}$ & 0.8215 & 6712 & -0.1212 & $1.278 \times 10^{-6}$ & 0.4253 \\
\hline Crack paste & 8135 & -0.1321 & $4.983 \times 10^{-6}$ & 0.5323 & 8135 & -0.1321 & $4.157 \times 10^{-6}$ & 0.2167 \\
\hline Stress absorption band & 15632 & -0.1032 & $5.4249 \times 10^{-7}$ & 0.2272 & 15632 & -0.1032 & $4.857 \times 10^{-7}$ & 0.1676 \\
\hline
\end{tabular}

The parameters $C_{1}$ and $C_{2}$ only rely on the number of initial cracking fatigue, so the same values have been exploited for both $2 \mathrm{D}$ and $3 \mathrm{D}$ calculations. As the fatigue life increases, the values of $C_{1}$ and $C_{2}$ increase. Further, the factors $C_{3}$ and $C_{4}$ are usually associated with the crack propagation process. Since different crack behaviors exist in the $2 \mathrm{D}$ and $3 \mathrm{D}$ models, the numerical results would be different. As the fatigue life increases, the value of $C_{3}$ grows while the factor $C_{4}$ reduces.

\section{Analysis of the XFEM Results}

4.1. Estimation of the Fatigue Life. By setting correct and reliable fatigue fracture parameters, the dynamic crack growth of treatment structures with crack pouring and the macromolecule polymer crack paste for both $2 \mathrm{D}$ and $3 \mathrm{D}$ states can be achieved. The relationship between the crack growth length $(a)$ and the number of wheel-load cycles $(N)$, when the cracks of the asphalt overlay expand from 3 to $30 \mathrm{~mm}$, can also be derived and compared with the results of the crack propagation obtained from the laboratory tests as demonstrated in Figures 7-9.

As can be seen in Figures 7 and 8, the overall trend of the variation of the crack propagation curves predicted by the XFEM is consistent with that of the results obtained from the laboratory test. The plots of the wheel load numbers of crack initiation and the crack termination cycles are also close to each other, and only a slight difference is observed in the crack propagation process. Specifically, the 3D-based model is more in line with the propagation process of the indoor test, and its crack propagation law is also more stable than the $2 \mathrm{D}$-based model. This is mainly related to the fact that the results of the 3D-based model are closer to the actual stress state of the indoor test model. Due to the plate's constraint, the crack propagation speed is slow, and the fatigue life is slightly higher than the test's. The 2D-based model does not consider the constraint effect of the incontact plate; thereby, the crack can be easily expanded, resulting in the fatigue life being smaller than the experimental value. Additionally, the crack propagation rate of the XFEM simulation is commonly faster than the indoor test value, especially at the initial stage of the crack propagation. This crucial fact is mainly related to the material forming characteristics of the asphalt mixture.

In the early stage of the test, the asphalt mixture is further compacted by wheel loading, which consumes the function and delays crack propagation. Nevertheless, the compaction process of the asphalt mixture has not been considered in the XFEM simulations. In the middle stage of the crack growth, both XFEM and laboratory tests have a relatively gentle stage

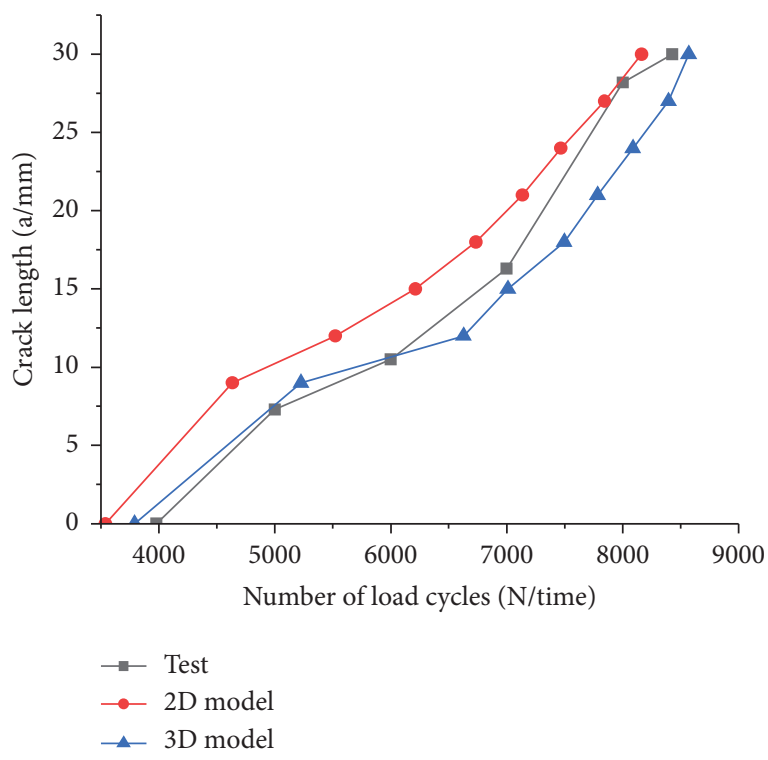

FIGURE 7: Crack propagation curves based on the crack pouring treatment.

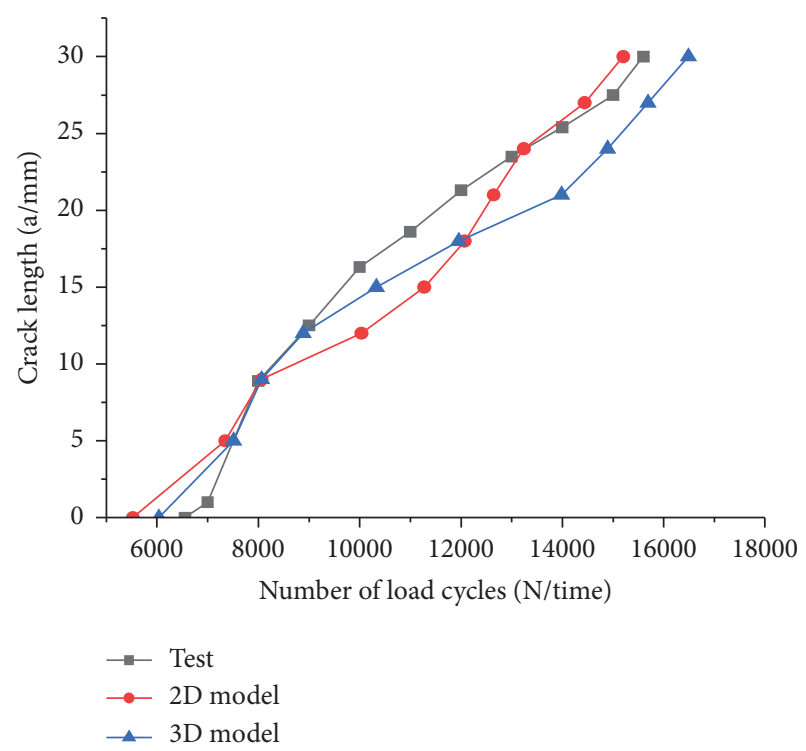

FIGURE 8: Crack propagation curves based on the macromolecule polymer crack paste treatment.

of crack growth, and the flexural tensile stress required for cracking would continuously lessen. Finally, since the effective height of the section as well as the stiffness decreases, the crack growth rate would rapidly grow until the crack runs through the whole asphalt overlay. 


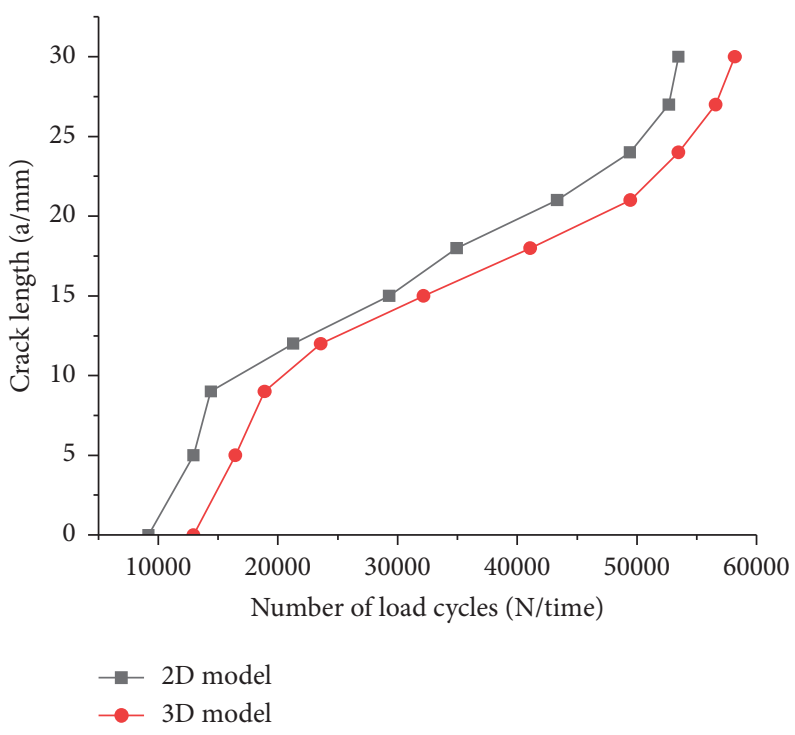

FIGURE 9: Crack propagation curves based on the high elastic stress. Absorption band treatment (without test results).

A comparison between the fatigue life results obtained from the laboratory test and those of the XFEM simulation is presented in Table 5. The loading times of the initial and final cracking based on the laboratory test and the XFEM simulations are mostly the same. The $2 \mathrm{D}$ relative error is less than $16 \%$, and the $3 \mathrm{D}$ calculations on the relative error are less than $8 \%$. It indicates that the XFEM can be effectively exploited to simulate reflection crack propagation and predict structural fatigue life.

4.2. Analysis of the Crack Propagation Law. The XFEM module in ABAQUS employs the level set method to describe the crack propagation position. The PHILSM and STAUTXFEM field variables are also utilized to output the crack surface and track the crack propagation path. The dynamic crack propagation process for the 3D-based model can be observed by extracting the variable cloud image in visualization, as shown in Figure 10. Further, the transverse crack propagation cannot be observed for the case of the $2 \mathrm{D}$ based model.

As shown in Figure 10, the tensile stress within the plate is less than those of the two ends due to the restraint of the plate at the early stage of cracking. The crack first initiated from both ends to the middle, forming the main crack through the width direction of the asphalt mixture. As the main crack extends upward, the damage gradually accumulates. After that, it reaches the critical fracture energy, and the crack slowly extends from the middle to both sides. The cracking behavior of the high elastic stress absorption band is slightly different from the other two methods, mainly in various cracking positions. The high elastic stress absorption band weakens the stress peak at both ends of the wheel track zone with its stress dissipation effect, and the first crack appears closer to the center of the wheel track with respect to the other two cases. The stress absorption band further increases the crack propagation path, making the crack propagate downward through the stress absorption band and then spread within the asphalt overlay.

In the XFEM numerical simulations, the crack propagation law is vertically upward and stable layer-by-layer cracking. However, the crack propagation in laboratory tests is not entirely vertical, mainly because the asphalt mixture is composed of gravel aggregate and asphalt cementitious material. By combining the results of the indoor model test and those of the XFEM analysis, the basic law of crack propagation of the asphalt overlay can be obtained. The crack initiation period of the asphalt mixture slab bottom occurs in the weak pore and initial defects of insufficient aggregate cementation. Under the action of repeated wheel loads, the crack propagates along the long axis of the defects, which is more obvious at the crack in the seam due to the stress centralization. The width of the transversely propagated crack in the asphalt mixture increases with the continuous growth of the crack width; then, the crack begins to appear at both ends. At this time, the crack penetrates the width of the whole plate to configure the main crack, leading to branch cracks' appearance. After the development of the main crack, the deflection of the asphalt overlay would significantly magnify, and the cracks extend from the bottom to the top by increasing the cyclic loading. In such circumferences, the effective height of the overlay section continuously decreases, and the cross section bending stiffness reduces until completing the fracturing process.

The cracking state of the asphalt mixture based on the $3 \mathrm{D}$ model is very consistent with the indoor test simulations. After the overlay structure is treated with crackresistant materials, its fatigue life of both initial and final cracks will increase, and the propagation speed of the main crack will slow down. It indicates that adopting the 3Dbased XFEM model is feasible to simulate the load fatigue cracking behavior of asphalt overlay structures after applying the crack resistance material treatment on the cement pavement. 
TABLE 5: Comparison between average values of the indoor test and the XFEM simulation results.

\begin{tabular}{lcccccc}
\hline \multirow{2}{*}{ Measures } & \multirow{2}{*}{ Crack propagation } & \multirow{2}{*}{ Test value } & \multicolumn{2}{c}{ 2D simulation results } & \multicolumn{2}{c}{ 3D simulation results } \\
& & & Cycle index & Error (\%) & Cycle index & Error (\%) \\
\hline \multirow{2}{*}{ Crack pouring } & Initial & 3979 & 3538 & 11.1 & 3790 & 4.7 \\
& Final & 8429 & 8163 & 3.2 & 8570 & 1.7 \\
\hline \multirow{2}{*}{ Crack paste } & Initial & 6554 & 5524 & 15.7 & 6040 & 7.8 \\
& Final & 15599 & 15204 & 2.5 & 16488 & 5.7 \\
\hline
\end{tabular}

PHILSM

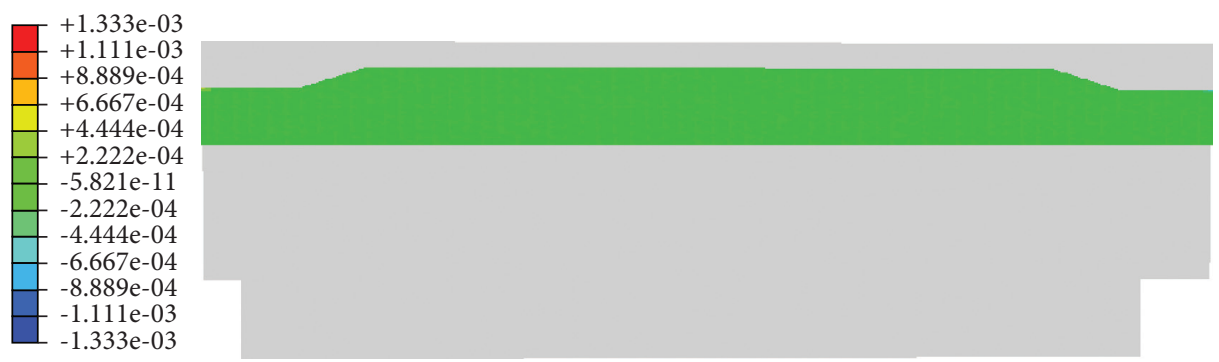

(a)

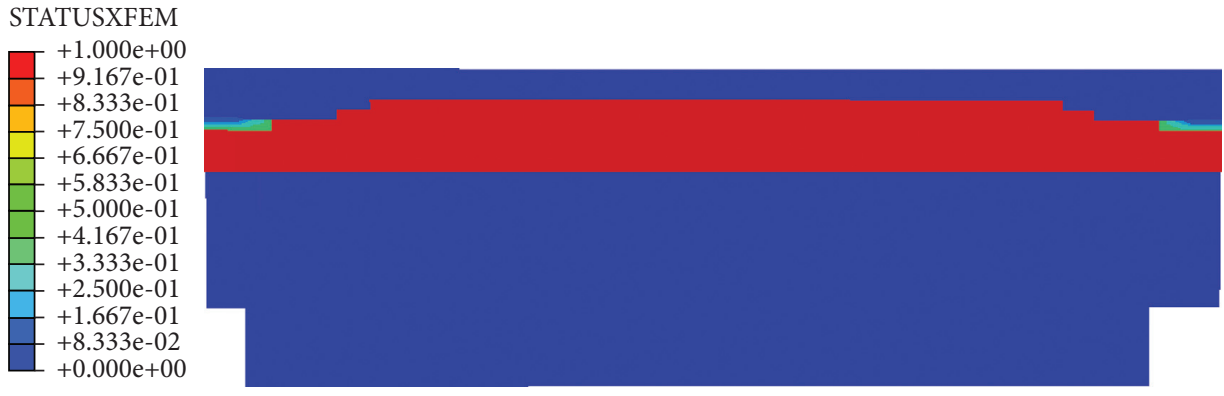

(b)

FIgURE 10: PHILSM and STAUTXFEM variable cloud charts of high elastic stress absorption band along the crack section direction when reaching 7010 times. (a) PHILSM variable cloud chart. (b) STAUTXFEM variable cloud chart. (Note. The green part in (a) represents the crack surface. The red part in (b) indicates that it has been cracked while the light green part indicates that it is near to being cracked.)

\section{Conclusions}

Through the indoor model test and XFEM method, the anticracking effect and crack propagation law of asphalt overlay structures were treated carefully. To this end, the crack pouring, macromolecule polymer crack paste, and high elastic stress absorption band are employed and analyzed in some detail. Some meaningful analysis results are obtained.

(1) The parameters pertinent to the improved Paris formula fracture for the asphalt mixture are obtained by fitting and calculating the $N$ - $a$ curve of the indoor fatigue test results. As the fatigue life increases, the fracture parameter values of $C_{1}, C_{2}$, and $C_{3}$ grow, while $C_{4}$ would gradually lessen.

(2) The XFEM is exploited to carry out 3D dynamic simulation and fatigue life prediction of the reflective crack of asphalt overlay layer structure after treatment of some of the cement pavement joint crack resistance material acted upon by the repeated wheel loads. The calculated results are in a reasonably good agreement with the laboratory test results, indicating that the XFEM can be effectively applied to the crack propagation law and fatigue life analysis of such engineering structures.

(3) The crack propagation law of asphalt mixture at the joint can be obtained by the indoor tests and XFEM simulations. The crack first occurs at the initial defect within the bottom of the asphalt layer at the joint and continues to extend along the long axis of the joint subjected to cyclic loading until transverse penetration. The main formed crack can be observed on the side of the edge, accompanied by multiple branch cracks. By the crack extending from bottom to top, the stiffness of the overlay structure continuously decreases until the crack extends to the road surface and it completely breaks.

(4) The results of the indoor test and the XFEM simulation analysis reveal that the crack-resistant materials of the cement concrete pavement joint could 
enhance the reflective cracking fatigue life of the asphalt overlay, and the influence of various anticracking materials is quite different. The anticracking effect is mainly reflected in the action times of the initial and final cracks, as well as the main crack propagation rate. Further, the high elastic stress absorption band has a superior crack resistance than the other two methods.

\section{Data Availability}

The data used to support the findings of this study are available from the corresponding author upon request.

\section{Conflicts of Interest}

The authors declare that they have no conflicts of interest regarding this work.

\section{Acknowledgments}

The authors would like to express their gratitude to EditSprings (https://www.editsprings.com/) for the expert linguistic services provided.

\section{References}

[1] W. Wang, S. Zhou, and Y. Qin, "Research progress of indoor reflective crack test method," Materials Reports, pp. 1-18, 2021.

[2] H. Guo, H. Sha, Y. Chou, X. Xu, and X. Wang, "Influence area analysis and reinforcement method of reflection crack in asphalt overlay of old cement road," Journal of China \& Foreign Highway, vol. 38, no. 4, pp. 49-53, 2018.

[3] Z. Tan, Y. Jiang, L. Guo, and Y. Zhou, "Thermal stresses in asphalt overlay paved on existing cement concrete pavements (III): thermal stresses analysis and local treatment effects," Journal of Tongji University, vol. 37, no. 3, pp. 333-338, 2009.

[4] R. Li, M. Liu, G. Zhou, H. Wang, and Z. Zhang, "Research on anti-reflection crack performance of DZFH new road anticracking paste," Journal of Chongqing Jianzhu University, vol. 36, no. 10, pp. 51-55, 2017.

[5] I. G. Torre, M. A. C. Perez, A. V. Zamanillo, and D. C. Fresno, "Evaluation of reflective cracking in pavements using a new procedure that combine loads with different frequencies," Construction and Building Materials, vol. 75, pp. 368-374, 2015.

[6] I. G. Torre, M. A. C. Perez, A. V. Zamanillo, and D. C. Fresno, "Experimental study of the behaviour of different geosynthetics as anti-reflective cracking systems using a combined-load fatigue test," Geotextiles and Geomembranes, vol. 43, no. 4, pp. 345-350, 2015.

[7] D. Z. Barraza, M. A. C. Pérez, D. C. Fresno, and A. V. Zamanillo, "Evaluation of anti-reflective cracking systems using geosynthetics in the interlayer zone," Geotextiles and Geomembranes, vol. 29, no. 2, pp. 130-136, 2011.

[8] Q. Li, H. J. Lee, and T. W. Kim, "A simple fatigue performance model of asphalt mixtures based on fracture energy," Construction and Building Materials, vol. 27, no. 1, pp. 605-611, 2012.

[9] Y. Seo and Y. R. Kim, "Using acoustic emission to monitor fatigue damage and healing in asphalt concrete," KSCE Journal of Civil Engineering, vol. 12, no. 4, pp. 237-243, 2008.
[10] E. V. Dave and W. G. Buttlar, "Thermal reflective cracking of asphalt concrete overlays," International Journal of Pavement Engineering, vol. 11, no. 6, pp. 477-488, 2010.

[11] M. Lopez, W. Fedrigo, T. R. Kleinert, M. F. Matuella, W. P. Nunez, and J. A. P. Ceratti, "Flexural fatigue evaluation of cement-treated mixtures of reclaimed asphalt pavement and crushed aggregates," Construction and Building Materials, vol. 158, pp. 320-325, 2017.

[12] I. Isailovic, M. P. Wistuba, and A. C. Falchetto, "Experimental study on asphalt mixture recovery," Materials and Structures, vol. 50, no. 4, p. 196, 2017.

[13] P. Liu, J. Chen, G. Lu, D. Wang, M. Oeser, and S. Leischner, "Numerical simulation of crack propagation in flexible asphalt pavements based on cohesive zone model developed from asphalt mixtures," Materials, vol. 12, no. 8, p. 1278, 2019.

[14] X. Q. Zhang, J. Wang, W. Wei, X. T. Ji, B. Chen, and G. W. Fang, "Simulation of fatigue cracks growth processes of two parallel cracks in thin plate pulled by the constant amplitude cyclic loading," Journal of the Brazilian Society of Mechanical Sciences and Engineering, vol. 41, no. 9, p. 374, 2019.

[15] N. Sukumar, N. Moes, and B. Moran, "Extended finite element method for three-dimensional crack modeling," International Journal for Numerical Methods in Engineering, vol. 37, no. 48, pp. 7161-7183, 2000.

[16] N. G. Kenny and D. Qingli, "Investigation of fracture behavior of heterogeneous infrastructure materials with extended-finite-element method and image analysis," Journal of Materials in Civil Engineering, vol. 23, no. 12, pp. 1662-1671, 2011.

[17] M. Yan, Study of Cracking Characteristic of Asphalt Mixture Based on Extend Finite Element Method, Dalian Maritime University, Dalian, China, 2012.

[18] G. Jin, Numerical Analysis of Fatigue Crack Growth in Asphalt Pavement Based on Extended Finite Element Mode, Southeast University, Nanjing, China, 2015.

[19] L. Huang, P. Zhang, Z. Hu, and W. Wu, "Fatigue propagation analysis of temperature shrinkage reflective crack in semirigid base asphalt pavement," Highway Engineer, vol. 45, no. 5, pp. 79-83, 2020.

[20] X. Wang and Y. Zhong, "Reflective crack in semi-rigid base asphalt pavement under temperature-traffic coupled dynamics using XFEM," Construction and Building Materials, vol. 214, pp. 280-289, 2019.

[21] M. R. Islam and M. J. Vallejo, "Crack propagation in hot mix asphalt overlay using extended finite-element model," Journal of Materials in Civil Engineering, vol. 29, no. 5, 2017.

[22] Z. Ma, Study on Residual Fatigue Life Prediction for Crack Damaged Offshore Platform Structures, Dalian University of Technology, Dalian, China, 2018.

[23] L. Guo, Z. Chen, J. Lou, and G. Chen, "A review of the extended finite element method and its applications," Chinese Quarterly of Mechanics, vol. 32, no. 4, pp. 612-625, 2011.

[24] X. Ni, X. Li, and J. Wang, "General modification and application of the Paris law for fatigue crack propagation," Pressure Vessel Technology, vol. 12, pp. 8-15, 2006. 